\title{
Role of p38 MAPK and JNK in enhanced cervical cancer cell killing by the combination of arsenic trioxide and ionizing radiation
}

\author{
YOUNG-HEE KANG and SU-JAE LEE \\ Laboratory of Molecular Biochemistry, Department of Chemistry, Hanyang University, Seoul 133-791, Korea
}

Received March 1, 2008; Accepted April 7, 2008

DOI: $10.3892 /$ or_00000053

\begin{abstract}
Enhancement of radiation response is possible to be achieved by combination treatment with therapeutic drugs. Previously we have shown that $\mathrm{As}_{2} \mathrm{O}_{3}$ in combination with ionizing radiation enhanced radiation response in cervical cancer cells. In this study, we further investigated molecular mechanism of synergistic enhancement of radiation response in combination with $\mathrm{As}_{2} \mathrm{O}_{3}$. The combination treatment of HeLa cells induced translocation of Bax to the mitochondria and a marked phosphorylation of Bcl-2.p38 MAPK and JNK were also found to be activated in response to the combination treatment. Pretreatment of PD169316, a p38 MAPK specific inhibitor, completely attenuated the combination treatmentinduced mitochondrial relocalization of Bax, and altered Bcl-2 phosphorylation. Moreover, pretreatment of SP600125, JNK specific inhibitor, clearly attenuated Bcl-2 phosphorylation, but did not affect Bax translocation to the mitochondria. In addition, N-acetyl-L-cysteine (NAC), a thiol-containing antioxidant, completely blocked p38 MAPK and JNK activations, Bax relocalization and Bcl-2 phosphorylation. These results indicate that activation of p38 MAPK is specifically required for translocation of Bax to the mitochondria, and both JNK and p38 MAPK are involved in phosphorylation of Bcl-2 in response to combination treatment with $\gamma$-radiation and $\mathrm{As}_{2} \mathrm{O}_{3}$, and that ROS is a critical regulator of p38 MAPK and JNK activations. The molecular mechanism elucidated in this study
\end{abstract}

Correspondence to: Dr Su-Jae Lee, Laboratory of Molecular Biochemistry, Department of Chemistry, Hanyang University, 17 Haengdang-Dong, Seongdong-Ku, Seoul 133-791, Korea E-mail: sj0420@hanyang.ac.kr

Abbreviations: APL, acute promyelocytic leukemia; MAPK, mitogen-activated protein kinase; JNK, c-Jun N-terminal protein kinase; AIF, apoptosis-inducing factor; ROS, reactive oxygen species; GSH, glutathione; NAC, N-acetylcysteine; PARP, poly ADP-ribose polymerase; $\operatorname{DiOC}_{6}(3), 3,3^{\prime}$ dihexylocarbocyanine iodide; PI, propidium iodide

Key words: arsenic trioxide $\left(\mathrm{As}_{2} \mathrm{O}_{3}\right)$, ROS generation, p38 MAPK, JNK, Bax translocaion, Bcl-2 phosphorylation, mitochondrial membrane potential loss, AIF release may provide insight into the design of future combination cancer therapies to cells intrinsically less sensitive to radiation treatment.

\section{Introduction}

Many factors affect susceptibility of tumor cells to ionizing radiation. Among them intrinsic apoptosis sensitivity or resistance seems to play an important role. The use of chemical modifiers as radiosensitizers in combination with low-dose irradiation may increase the therapeutic efficacy by overcoming a high apoptotic threshold. Arsenic has long been used as anticancer agent in traditional Chinese medicine (1). Recently arsenic trioxide $\left(\mathrm{As}_{2} \mathrm{O}_{3}\right)$ has been successfully employed in treatment of refractory or relapsed acute promyelocytic leukemia (APL), and its efficacy has been confirmed even in patients resistant to conventional chemotherapy $(2,3)$. We and others reported that $\mathrm{As}_{2} \mathrm{O}_{3}$ is an effective inducer of apoptotic cell death in vitro in various solid tumor cells, such as esophageal, prostate, ovarian carcinomas, neuroblastoma, and cervical cancer cells (4-7).

One of the important points in the development of a new anti-cancer drug is the understanding of its potential for inclusion in combination treatment regimen. Several recent studies demonstrated additive effects of $\mathrm{As}_{2} \mathrm{O}_{3}$ with conventional chemotherapeutic agents such as cisplatin, adriamycin and etoposide, but no synergism. Previously, we showed that $\mathrm{As}_{2} \mathrm{O}_{3}$ sensitize human cervical cancer cells to ionizing radiation (8). Treatment of $\mathrm{As}_{2} \mathrm{O}_{3}$ in combination of ionizing radiation has synergistic effects in decreasing clonogenic survival and in the regression of tumor growth in xenografts. We also have shown that the combination treatment enhanced apoptotic cell death through a reactive oxygen species (ROS)-dependent pathway in human cervical cancer cells. The combination treatment of HeLa cells increased intracellular ROS level, and induced loss of the mitochondrial membrane potential and caspase activation. The combination treatment-induced cell death was completely blocked by the antioxidant, suggesting ROS-dependent cell death pathway is employed. However, precise signaling pathways for the ROS-mediated mitochondrial apoptotic cell death triggered by the combination treatment with $\mathrm{As}_{2} \mathrm{O}_{3}$ and ionizing radiation still remains unclear, especially in solid cancer cells. 
In this study, we investigated the cross talk between MAPK signaling and mitochondrial apoptotic cell death induced by combination treatment with $\mathrm{As}_{2} \mathrm{O}_{3}$ and ionizing radiation in human cervical cancer cells. We showed that ROS-dependent activations of p38 MAPK and JNK are critically required for the mitochondrial apoptotic cell death in response to the combination treatment.

\section{Materials and methods}

Materials. $\mathrm{As}_{2} \mathrm{O}_{3}$ was purchased from Sigma (St. Louis, MO). Antibodies against Bax, $\alpha$-tubulin, heat shock protein 60, AIF, p38 MAPK, ERK2 and caspase-9 were obtained from Santa Cruz Biotechnology, Inc. (Santa Cruz, CA). Anti- $\beta$-actin was from Sigma. Antibodies against cytochrome c, Bcl-2 and JNK1 were from BD Bioscience PharMingen (San Jose, CA). Antibodies against phospho-p38, phoso-JNK 1/2, phosphor-ERK1/2, JNK1/2, ERK1/2, PARP and caspase-3 were obtained from Cell Signaling Technology (Beverly, MA, USA). Inhibitors specific to JNK (SP600125), MEK (PD98059) and p38 MAPK (PD169316) were from Calbiochem (San Diego, CA). N-acetyl-L-cystein (NAC) was from Sigma.

Cell culture. HeLa cells were obtained from the American Type Culture Collection. HeLa cells were grown in Roswell Park Memorial Institute 1640 medium supplemented with $10 \%$ fetal bovine serum, 100 units $/ \mathrm{ml}$ penicillin and $100 \mu \mathrm{g} / \mathrm{ml}$ streptomycin.

Irradiation. Cells were plated in 6- or $10-\mathrm{cm}$ dishes and incubated at $37^{\circ} \mathrm{C}$ under humidified $5 \% \mathrm{CO}_{2}-95 \%$ air in culture medium until $70-80 \%$ confluent. Cells were then exposed to $\gamma$-rays with ${ }^{137} \mathrm{Cs} \gamma$-ray source (Atomic Energy of Canada, Ltd., Canada) with a dose rate of $3.81 \mathrm{~Gy} / \mathrm{min}$.

Quantification of cell death. For the cell death assessment, the cells were plated in 6-well plates with cell density of $1 \times 10^{5}$ cells per well and treated with 6 Gy of $\gamma$-radiation alone, $1.5 \mu \mathrm{M}$ of $\mathrm{As}_{2} \mathrm{O}_{3}$ alone, or combination of $\gamma$-radiation (6 Gy) and $\mathrm{As}_{2} \mathrm{O}_{3}(1.5 \mu \mathrm{M})$ the next day. At indicated time points, cells were trypsinized, washed in phosphatebuffered saline (PBS) and then incubated in propidium iodide $\left(2.5 \mathrm{mg} \mathrm{ml}^{-1}\right)$ for $5 \mathrm{~min}$ at room temperature and analyzed with a flow cytometer.

Measurement of mitochondrial membrane potential and ROS generation. Cells $\left(5 \times 10^{5} / \mathrm{ml}\right)$ were exposed to $6 \mathrm{~Gy}$ of $\gamma$-radiation and/or $1.5 \mu \mathrm{M}$ of $\mathrm{As}_{2} \mathrm{O}_{3}$ for the indicated times. After exposure, cells were incubated in $30 \mathrm{nM} \mathrm{3,3'-dihexy-}$ loxacarboxyanine iodide $\left(\mathrm{DiO}_{6}(3)\right)$, and $10 \mu \mathrm{M}$ DCFH-DA (Molecular Probes, Eugene, OR) at $37^{\circ} \mathrm{C}$ for $30 \mathrm{~min}$, and harvested by trypsinization and washed with cold PBS solution three times. ROS and $\Delta \psi_{\mathrm{m}}$ were determined by FACS analysis.

Western blot analysis. Western blot analysis was performed as described. Briefly, cell lysates were prepared by extracting proteins with lysis buffer [40 mM Tris-Cl (pH 8.0), $120 \mathrm{mM}$
$\mathrm{NaCl}, 0.1 \%$ Nonidet-P40] supplemented with protease inhibitors. Proteins were separated by SDS-PAGE and transferred to nitrocellulose membranes (Bio-Rad). The membranes were blocked with $5 \%$ non-fat dry milk in Tris buffered saline and then incubated with primary antibodies for $1 \mathrm{~h}$ at room temperature. Blots were developed by peroxidase-conjugated secondary antibody, and proteins were visualized by enhanced chemiluminescence (ECL) procedures (Amersham Biosciences) according to the manufacturer's recommendations.

Immunocomplex kinase assays. Cells were harvested and lysed with buffer A containing $50 \mathrm{mM}$ Tris- $\mathrm{HCl}(\mathrm{pH} 7.5)$, $150 \mathrm{mM} \mathrm{NaCl}, 1 \mathrm{mM}$ phenylmethylsulfonyl fluoride, $2 \mu \mathrm{g}$ of leupeptin/ml, $2 \mu \mathrm{g}$ of aprotinin/ml, $25 \mathrm{mM}$ glycerophosphate, $0.1 \mathrm{mM}$ sodium orthovanadate, $1 \mathrm{mM}$ sodium fluoride, $1 \%$ Nonidet P-40, $0.5 \%$ sodium deoxycholate and $0.1 \%$ sodium dodecyl sulfate (SDS). Cell lysates were subjected to centrifugation at $12,000 \mathrm{x}$ g for $15 \mathrm{~min}$ at $4^{\circ} \mathrm{C}$. The resulting supernatant was subjected to immunoprecipitation by incubation first for $2 \mathrm{~h}$ at $4^{\circ} \mathrm{C}$ with appropriate antibodies and then for $1 \mathrm{~h}$ at $4^{\circ} \mathrm{C}$ in the additional presence of protein A-Sepharose (Sigma). Immunoprecipitates were assayed for the indicated protein kinase activities by using fusion proteins as substrate. Reaction mixtures were were analyzed by SDSPAGE and autoradiography. GST-c-jun (Cell Signaling), GST-ATF2 (Santa Cruz) and MBP (Upstate) were used as substrates for JNK1, p38 MAPK and ERK2, respectively.

Preparation of cytosolic and mitochondrial fractions. Cells were collected and washed twice in ice-cold PBS, resuspended in S-100 buffer [20 mM HEPES, pH 7.5, $10 \mathrm{mM} \mathrm{KCl,} 1.9 \mathrm{mM}$ $\mathrm{MgCl}_{2}, 1 \mathrm{mM}$ EGTA, $1 \mathrm{mM}$ EDTA, mixture of protease inhibitors] and incubated on ice for $20 \mathrm{~min}$. After 20-min incubation on ice, the cells were homogenized with a Dounce glass homogenizer and a loose pestle (Wheaton, Millville, NJ) for 70 strokes. Cell homogenates were spun at $1,000 \times \mathrm{g}$ to remove unbroken cells, nuclei and heavy membranes. The supernatant was re-spun at 14,000 $\mathrm{x} g$ for $30 \mathrm{~min}$ to collect the mitochondria-rich (the pellet) and the cytosolic (the supernatant) fractions. The mitochondria-rich fraction was washed once with the extraction buffer, followed by a final resuspension in lysis buffer $(150 \mathrm{mM} \mathrm{NaCl}, 50 \mathrm{mM}$ Tris-Cl, pH 7.4, $1 \%$ NP-40, $0.25 \%$ sodium deoxycholate, $1 \mathrm{mM}$ EGTA) containing protease inhibitors for Western blot analysis.

\section{Results}

We first examined whether ionizing radiation treatment in combination with $\mathrm{As}_{2} \mathrm{O}_{3}$ had a synergistic effect on cell death in HeLa cells. As shown in Fig. 1A, the combination treatment indeed synergistically enhanced the apoptotic cell death of HeLa cells in a time-dependent manner. However, treatment of cells with radiation (6 Gy) did not show any effect on cell death. In addition, $\mathrm{As}_{2} \mathrm{O}_{3}$ alone $(1.5 \mu \mathrm{M})$ showed a subtle cytotoxic effect. To determine whether mitochondrial pathway is involved in induction of the apoptotic cell death seen after combination treatment, we examined changes in mitochondrial membrane potential and cytochrome $\mathrm{c}$ release from 
A
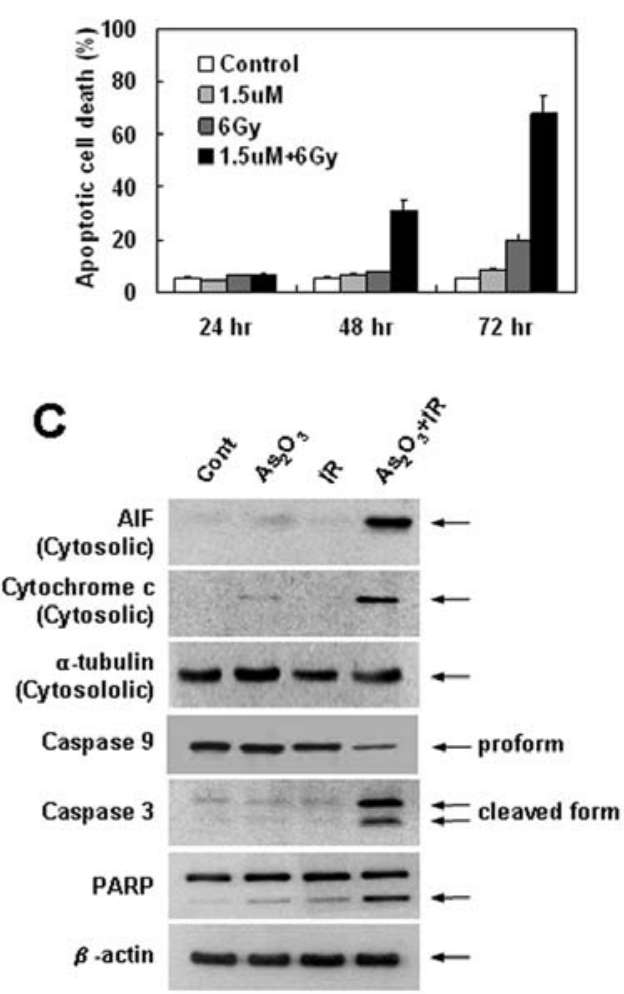

B
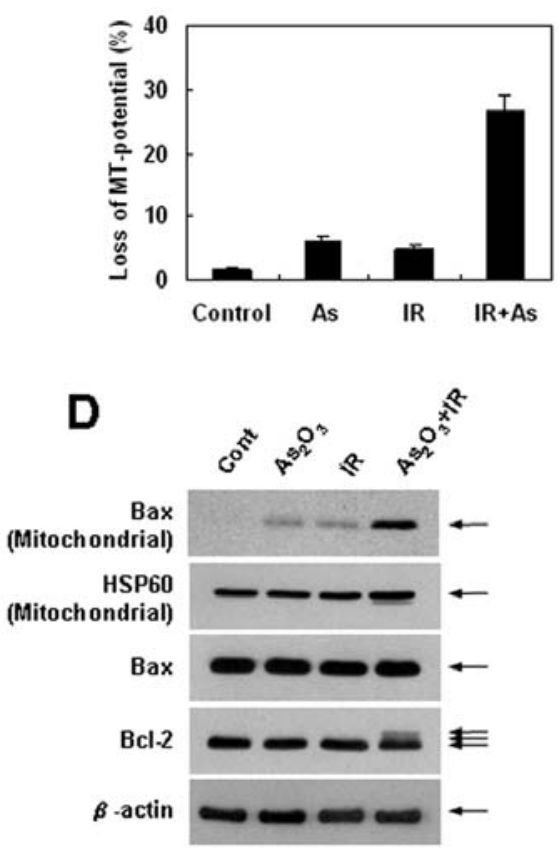

Figure 1. $\mathrm{As}_{2} \mathrm{O}_{3}$ in combination with $\gamma$-radiation enhances apoptotic cell death. (A) HeLa cells were treated with 6 Gy of $\gamma$-radiation alone, $1.5 \mu \mathrm{M}$ of $\mathrm{As}_{2} \mathrm{O}_{3}$ alone, or combination of $\gamma$-radiation $(6 \mathrm{~Gy})$ and $\mathrm{As}_{2} \mathrm{O}_{3}(1.5 \mu \mathrm{M})$. After 24,48 and $72 \mathrm{~h}$, cell death was determined by flow cytometric analysis described in Materials and methods. Results from three independent experiments are shown as means \pm SEM. (B) Cells were treated with 6 Gy of $\gamma$-radiation and/or $1.5 \mu \mathrm{M}$ of $\mathrm{As}_{2} \mathrm{O}_{3}$. After $48 \mathrm{~h}$, mitochondrial transmembrane potential of these cells was determined by retention of DiOC 6 (3) added during the last 30 min of treatments with a flow cytometry. Results from three independent experiments are shown as means \pm SEM. (C) Cells were treated with 6 Gy of $\gamma$-radiation and/or $1.5 \mu \mathrm{M}$ of $\mathrm{As}_{2} \mathrm{O}_{3}$. After $48 \mathrm{~h}$, cytosolic fraction was obtained and subjected to Western blot analysis with anti-AIF, -cytochrome c or - $\alpha$-tubulin antibodies. $\alpha$-tubulin was used as a cytosolic marker protein. Cell extracts were also examined directly by Western blot analysis with antibody to caspase-9, caspase-3, PARP and $\beta$-actin. $\beta$-actin was used as a loading control. (D) $\mathrm{As}_{2} \mathrm{O}_{3}$ in combination with $\gamma$-radiation induces Bax translocation to mitochondria and Bac-2 phosphorylation. Subcellular fractionation was performed with the cells treated with 6 Gy of $\gamma$-radiation and/or $1.5 \mu \mathrm{M}$ of As $\mathrm{O}_{3}$ for 48 h. Mitochondrial fractions were subjected to Western blot analysis with anti-Bax and -HSP60 antibodies. HSP60 was used as a mitochondrial marker protein. Cells were treated with $6 \mathrm{~Gy}$ of $\gamma$-radiation and/or $1.5 \mu \mathrm{M}$ of $\mathrm{As}_{2} \mathrm{O}_{3}$. After $48 \mathrm{~h}$, cell extracts were subjected to Western blot analysis with anti-Bax, -Bcl-2 and $\beta$-actin antibodies. $\beta$-actin was used as a loading control.

the mitochondria into the cytosol after the combination treatment. Radiation in combination with $\mathrm{As}_{2} \mathrm{O}_{3}$ significantly disrupted mitochondrial membrane potential (Fig. 1B). At the same time, level of the cytosolic AIF and cytochrome c was markedly increased (Fig. 1C), coinciding with changes in mitochondrial membrane potential. Combination treatment with radiation and $\mathrm{As}_{2} \mathrm{O}_{3}$ also caused activation of caspase-9 and caspase-3, and cleavage of poly ADP-ribose polymerase (PARP) (Fig. 1C). However, we failed to detect caspase- 8 and Bid cleavage (data not shown). These results indicate that radiation treatment in combination with $\mathrm{As}_{2} \mathrm{O}_{3}$ induces synergistic apoptotic cell death in mitochondrial dysfunction-dependent manner.

Because it has been shown that translocation of Bax from the cytosol to the mitochondria causes a decline of mitochondrial membrane potential (9-14), we investigated whether the combination treatment with $\mathrm{As}_{2} \mathrm{O}_{3}$ and $\gamma$-radiation induces mitochondrial translocation of Bax. As shown in Fig. 1D, the combination treatment redistributed Bax from cytosol to the mitochondria without changing the protein level, suggesting that activation of Bax involves the combination treatment- induced mitochondrial apoptotic cell death pathway. Since the phosphorylation of Bcl-2 is critically involved in the mitochondrial apoptotic process in response to various stimuli (15-19), we examined whether the combination treatment induces phosphorylation of Bcl-2. As shown in Fig. 1D, the combination treatment of HeLa cells with radiation and $\mathrm{As}_{2} \mathrm{O}_{3}$ resulted in the expression of slower-migrating (phosphorylated) forms of $\mathrm{Bcl}-2$ protein. The slower-migrating forms of Bcl-2 have been shown by studies published previously (20) to represent phosphorylated forms of the protein. Therefore, this result indicate that phosphorylation of Bcl-2 is also involved in synergistic enhancement of mitochondrial apoptotic cell death in response to combination treatment with $\gamma$-radiation and $\mathrm{As}_{2} \mathrm{O}_{3}$.

Mitogen-activated protein kinases (MAPKs) have been implicated in regulation of apoptotic cell death in response to various stimuli. To investigate a potential involvement of MAPKs in the enhancement of mitochondrial apoptotic cell death induced by the combination treatment with radiation and $\mathrm{As}_{2} \mathrm{O}_{3}$, we first examined changes in MAPK activities after the combination treatment using immune-complex kinase 


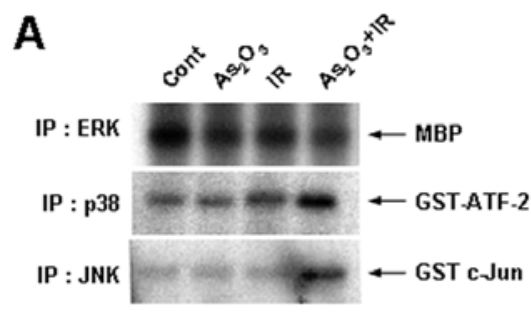

\section{B}

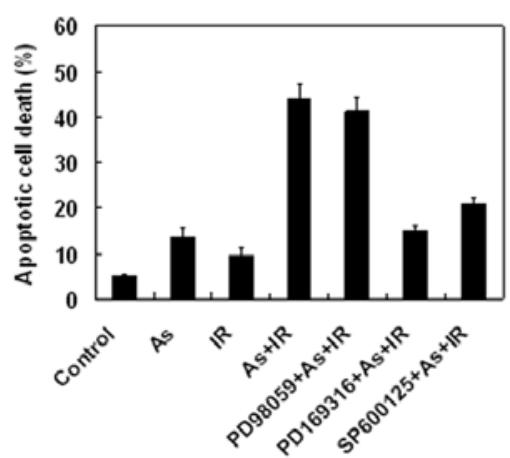

E

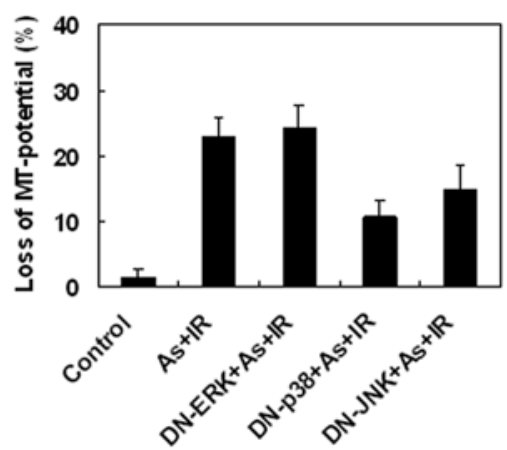

C

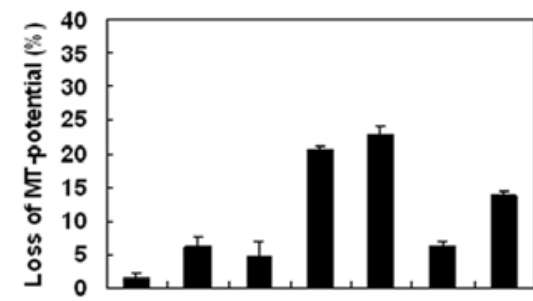

D<smiles>CC[C@H]1C=C[C@H]2C=C[C@H]1C2</smiles>

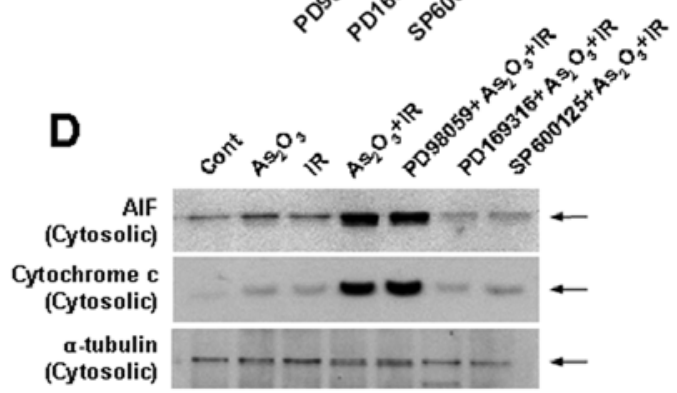

$\mathbf{F}$

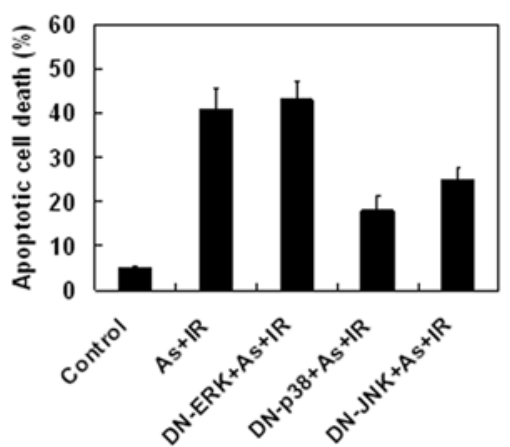

Figure 2. Activations of p38 MAPK and JNK are involved in the combination treatment-induced apoptotic cell death. (A) HeLa cells were treated with 6 Gy of $\gamma$-radiation alone, $1.5 \mu \mathrm{M}$ of $\mathrm{As}_{2} \mathrm{O}_{3}$ alone, or combination of $\gamma$-radiation (6 Gy) and $\mathrm{As}_{2} \mathrm{O}_{3}(1.5 \mu \mathrm{M})$. After $48 \mathrm{~h}$, proteins were subjected to immune complex kinase assay with anti-ERK, -p38 MAPK and -JNK antibodies. MBP, GST-ATF-2 and GST-c-Jun were used as substrates for ERK, p38 MAPK and JNK, respectively. (B) HeLa cells were treated with $6 \mathrm{~Gy}$ of $\gamma$-radiation and/or $1.5 \mu \mathrm{M}$ of $\mathrm{As}_{2} \mathrm{O}_{3}$ in the presence of JNK specific inhibitor, SP600125 (20 $\mu \mathrm{M}$ ), p38 MAPK specific inhibitor, PD169316 (20 $\mu \mathrm{M})$, or MEK specific inhibitor, PD98059 (40 $\mu \mathrm{M})$. After $48 \mathrm{~h}$, cell death was determined by flow cytometric analysis described in Materials and methods. Results from three independent experiments are shown as means \pm SEM. (C) After 48 h, mitochondrial transmembrane potential of these cells was determined by retention of $\mathrm{DiOC}_{6}(3)$ added during the last 30 min of treatments with a flow cytometry. Results from three independent experiments are shown as means \pm SEM. (D) After 48 h, cytosolic fraction was obtained and subjected to Western blot analysis with anti-AIF, -cytochrome c or - $\alpha$-tubulin antibodies. $\alpha$-tubulin was used as a cytosolic marker protein. (E) HeLa cells were treated with 6 Gy of $\gamma$-radiation and/or $1.5 \mu \mathrm{M}$ of $\mathrm{As}_{2} \mathrm{O}_{3}$ in the presence or absence of dominant negative forms of ERK, JNK, and p38MAPK. After $48 \mathrm{~h}$, mitochondrial transmembrane potential was determined by retention of $\operatorname{DiOC}_{6}(3)$ added during the last 30 min of treatments with a flow cytometry. (F) After $48 \mathrm{~h}$, cell death was determined by flow cytometric analysis described in Materials and methods.

assay. As shown in Fig. 2A, the combination treatment led to dramatic increase of the p38 MAPK and JNK activities, but did not affect ERK activity. However, the total cellular levels of MAPKs remained constant (data not shown). To determine whether activations of p38 MAPK and JNK are involved in the combination treatment-induced apoptotic cell death, we employed specific inhibitors of p38 MAPK or JNK. Pretreatment of PD169316, a p38 MAPK specific inhibitor, and SP600125, a JNK-specific inhibitor, effectively attenuated the combination treatment-induced apoptotic cell death, while MEK/ERK inhibitor, PD98059, did not (Fig. 2B). Pretreatment of PD169316 and SP600125 also inhibited mitochondrial membrane potential loss (Fig. 2C), release of cytochrome c and AIF from mitochondria (Fig. 2D) induced by the combination treatment. Moreover, ectopic expression of dominant negative mutant forms of p38MAPK or JNK also effectively suppressed the combination treatment-induced mitochondrial membrane potential loss (Fig. 2E) and mitochondrial cell death (Fig. 2F). In addition, p38 MAPK inhibition showed more potent attenuation of mitochondrial apoptotic cell death than JNK inhibition. These results indicate that p38 MAPK and JNK act as important mediators of the combination treatment-induced mitochondrial apoptotic cell death in human cervical cancer cells. 


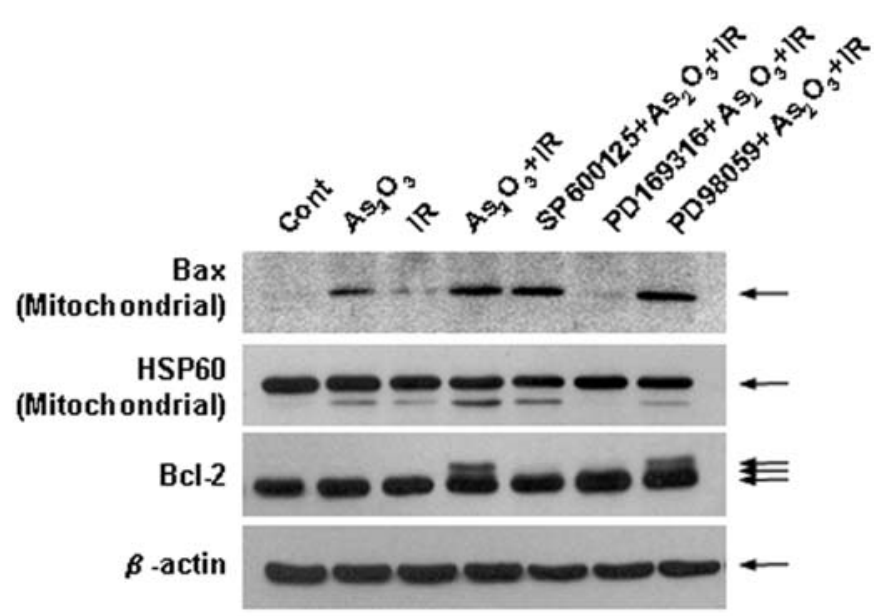

Figure 3. Activation of p38 MAPK is specifically required for translocation of Bax to the mitochondria, and both JNK and p38 MAPK are involved in phosphorylation of $\mathrm{Bcl}-2$ in response to combination treatment with $\gamma$-radiation and $\mathrm{As}_{2} \mathrm{O}_{3}$. HeLa cells were treated with 6 Gy of $\gamma$-radiation alone, $1.5 \mu \mathrm{M}$ of $\mathrm{As}_{2} \mathrm{O}_{3}$ alone, or combination of $\gamma$-radiation (6 Gy) and $\mathrm{As}_{2} \mathrm{O}_{3}(1.5 \mu \mathrm{M})$ in the presence of JNK specific inhibitor, SP600125, p38 MAPK specific inhibitor, PD169316, or MEK specific inhibitor, PD98059. After $48 \mathrm{~h}$, mitochondrial fractions was obtained and subjected to Western blot analysis with anti-Bax and -HSP60 antibodies. HSP60 was used as a mitochondrial marker protein. Cells were treated with 6 Gy of $\gamma$-radiation and/or $1.5 \mu \mathrm{M}$ of $\mathrm{As}_{2} \mathrm{O}_{3}$. After $48 \mathrm{~h}$, cell extracts were subjected to Western blot analysis with anti-Bcl-2 and $B$-actin antibodies. $B$-actin was used as a loading control.

We further examined whether p38 MAPK and JNK are involved in Bax translocation to the mitochondria and/ or Bcl-2 phosphorylation in response to the combination treatment. As shown in Fig. 3, pretreatment of PD169316, a p38 MAPK specific inhibitor, completely attenuated the combination treatment-induced relocalization of Bax to the mitochondria, and also altered $\mathrm{Bcl}-2$ phosphorylation. On the other hand, treatment with SP600125, a JNK specific inhibitor, suppressed the combination treatment-induced Bcl-2 phosphorylation, but did not affect mitochondrial relocalization of Bax. In addition, pretreatment of PD98059, a MEK/ERK specific inhibitor did not alter either Bax translocation or Bcl-2 phosphorylation. These results indicate that activation of p38 MAPK is specifically required for translocation of Bax to the mitochondria, and both JNK and p38 MAPK are involved in phosphorylation of Bcl-2 in response to combination treatment with $\gamma$-radiation and $\mathrm{As}_{2} \mathrm{O}_{3}$.

We previously showed that reactive oxygen species (ROS) plays a critical role in synergistic enhancement of apoptotic cell death by the combination treatment with radiation and $\mathrm{As}_{2} \mathrm{O}_{3}$ in human cervical cancer cells (8). We further examined whether generation of ROS induced by the combination treatment is required for p38 MAPK and JNK activations and their mediated alteration of Bcl-2 family proteins. To determine a linkage between elevation of the intracellular ROS level and p38 MAPK and JNK activations in response to the combination treatment, HeLa cells were preincubated with thiol-containing antioxidant N-acetyl-L-cysteine (NAC) prior to the combination treatment. Pretreatment of NAC completely suppressed the combination treatment-induced p38 MAPK and JNK activations (Fig. 4B) as well as ROS generation (Fig. 4A). In addition, pretreatment of NAC completely attenuated Bax translocation to the mitochondria, Bcl-2 phosphorylation (Fig. 4C), cytochrome c and AIF release (Fig. 4D) and subsequent apoptotic cell death (Fig. 4E). These observations suggest that increase in the intracellular ROS level after the combination treatment is required for p38 MAPK and JNK activations accompanied by the mitochondrial apoptotic cell death.

\section{Discussion}

The use of chemical modifiers as radiosensitizers in combination with low-dose irradiation may increase the therapeutic efficacy by overcoming a high apoptotic threshold. The aim of our investigation was to elucidate molecular mechanism of the synergistic apoptotic cell death triggered by combination treatment with ionizing radiation and $\mathrm{As}_{2} \mathrm{O}_{3}$ in human cervical cancer cells.

We previously demonstrated that $\mathrm{As}_{2} \mathrm{O}_{3}$ in combination with $\gamma$-radiation have a synergistic effect in dissipation of mitochondrial membrane potential, thereby enhancing apoptotic cell death in human cervical cancer cells (8). In the present study, we provided further evidence that translocation of Bax to the mitochondria and phosphorylation of Bcl-2 are two critical events leading to mitochondrial membrane potential loss in response to the combination treatment. The mitochondrial activation-mediated apoptosis pathway has been shown to be required for Fas-induced apoptosis in certain cell types that are classified as type II cells $(21,22)$. In these cells, Bid, the BH3-only protein of the Bcl-2 family, are activated by post-translational modification in a caspase- 8 dependent manner, and induces the Bax activation (23-25) and subsequent mitochondrial membrane potential loss. However, we failed to detect any changes in caspase- 8 and $\mathrm{Bid}$ in response to the combination treatment (data not shown), suggesting that Bax translocation to the mitochondria and subsequent mitochondrial membrane potential loss induced by combination treatment with $\gamma$ radiation and $\mathrm{As}_{2} \mathrm{O}_{3}$ is caspase- 8 and $\mathrm{Bid}$ independent. p38 MAPK has been positively implicated in induction of apoptosis in response to various stress signals including TNF- $\alpha$, interleukin-1, UV irradiation, hyperosmotic stress and chemotherapeutic drugs (26-29). Consistent with these findings, we found that p38 MAPK is involved in the combination treatment-induced mitochondrial apoptotic cell death. Inhibition of p38 MAPK with pretreatment of specific chemical inhibitor completely attenuated mitochondrial translocation of $\mathrm{Bax}$ in response to the combination treatment, suggesting that p38 MAPK is critically required for the Bax relocalization to the mitochondria.

Several reports have demonstrated the hypothesis that the anti-apoptotic function of Bcl-2 is dependent on its phosphorylation status rather than its expression level $(20,30)$. An abrogation in anti-apoptotic function of Bcl-2 due to its phosphorylation has been demonstrated in cells treated with Taxol or other microtubule-targeting anticancer agents $(20,31)$. Consistent with these findings, we observed that the combination treatment-induced Bcl-2 phosphorylation is closely associated with JNK and p38 MAPK activations. Pre- 
A
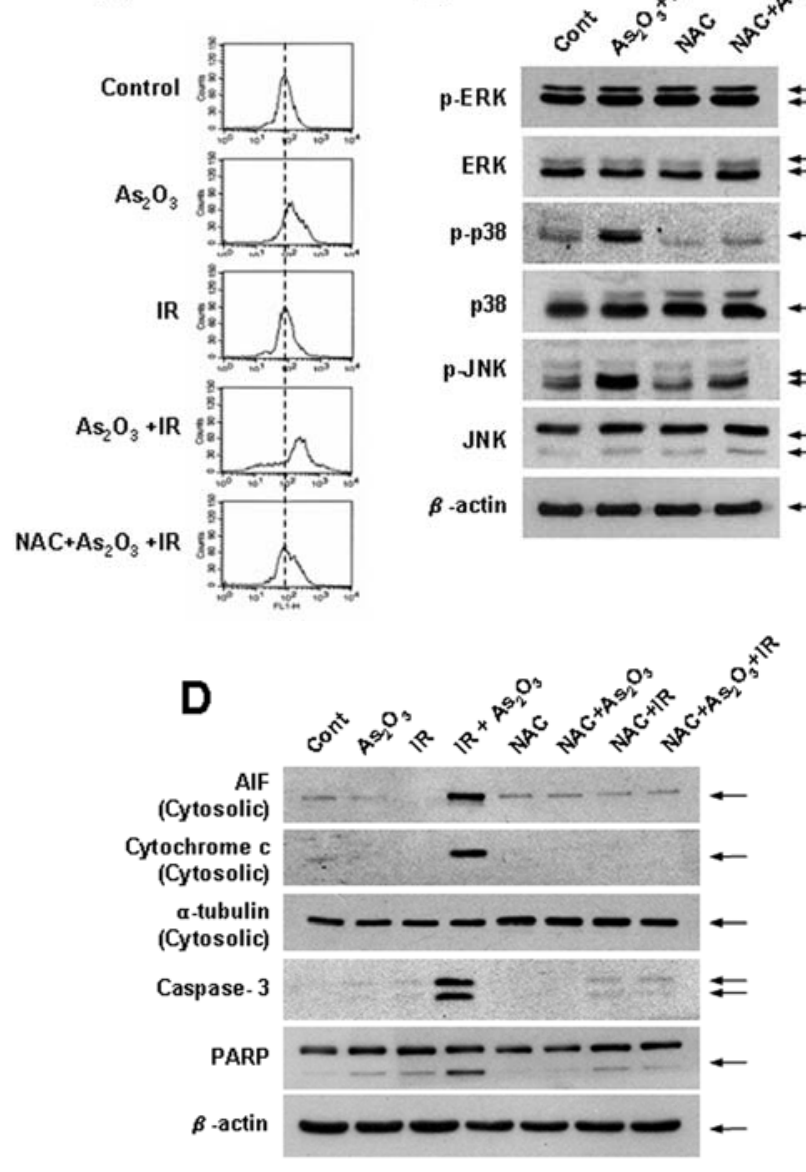

B

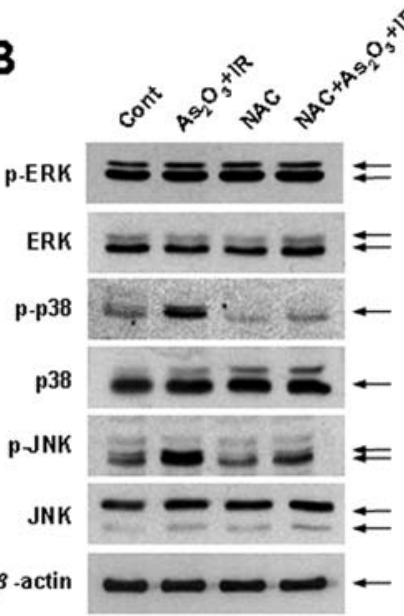

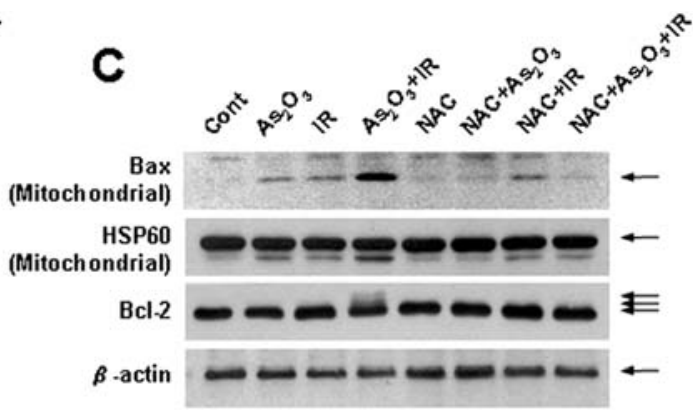

E

Figure 4. The role of ROS in apoptotic cell death of radiation-resistant cancer cells induced by combination treatment with $\gamma$-radiation and $\mathrm{As} \mathrm{O}_{2}$. (A) HeLa cells were loaded with DCFH-DA and further stimulated with 6 Gy of $\gamma$-radiation and/or $1.5 \mu \mathrm{M}$ of $\mathrm{As}_{2} \mathrm{O}_{3}$ in the presence or absence of N-acetylcysteine (NAC) $(10 \mathrm{mM})$. After $48 \mathrm{~h}$, the amount of DCF fluorescence was measured using flow cytometry. (B) HeLa cells were treated with 6 Gy of $\gamma$-radiation and/or $1.5 \mu \mathrm{M}$ of $\mathrm{As}_{2} \mathrm{O}_{3}$ in the presence or absence of NAC (10 mM). After 48, proteins were subjected to Western blot analysis with anti-phospho-p38, phospho-JNK, -phospho-ERK, -p38, -JNK, -ERK and -ß-actin antibodies. B-actin was used as a loading control. (C) Subcellular fractionation was performed with the cells treated with $6 \mathrm{~Gy}$ of $\gamma$-radiation and/or $1.5 \mu \mathrm{M}$ of $\mathrm{As}_{2} \mathrm{O}_{3}$ in the presence or absence of NAC (10 mM) for $48 \mathrm{~h}$. Mitochondrial fractions were subjected to Western blot analysis with anti-Bax and -HSP60 antibodies. HSP60 was used as a mitochondrial marker protein. Cells were treated with 6 Gy of $\gamma$-radiation and/or $1.5 \mu \mathrm{M}$ of $\mathrm{As}_{2} \mathrm{O}_{3}$ in the presence or absence of NAC $(10 \mathrm{mM})$. After $48 \mathrm{~h}$, cell extracts were subjected to Western blot analysis with antiBcl-2 and $\beta$-actin antibodies. $\beta$-actin was used as a loading control. (D) HeLa cells were treated with 6 Gy of $\gamma$-radiation and/or $1.5 \mu \mathrm{M}$ of As $\mathrm{O}_{3}$ in the presence or absence of NAC (10 mM). After $48 \mathrm{~h}$, cytosolic fraction was obtained and subjected to Western blot analysis with anti-AIF, -cytochrome c or - $\alpha$ tubulin antibodies. $\alpha$-tubulin was used as a cytosolic marker protein. Cell extracts were also examined directly by Western blot analysis with antibody to caspase-3, PARP and B-actin. $\beta$-actin was used as a loading control. (E) HeLa cells were treated with 6 Gy of $\gamma$-radiation and/or $1.5 \mu \mathrm{M}$ of As $\mathrm{O}_{3}$ in the presence or absence of NAC (10 mM). After $48 \mathrm{~h}$, cell death was determined by flow cytometric analysis described in Materials and methods. Results from three independent experiments are shown as means \pm SEM.

treatment of JNK or p38 MAPK specific inhibitors, attenuated phosphorylation of $\mathrm{Bcl}-2$ induced by the combination treatment, indicating that JNK and p38 MAPK are upstream regulators for the phosphorylation of $\mathrm{Bcl}-2$.

Many studies have shown that ROS producing agents lead to activation of the MAP kinases $(32,33)$. Modulation of GSH levels also plays a role in the activation of JNK and p38 MAPK, as shown after treatment with alkylating agents $(34,35)$. Consistent with these findings, we also found that the increased intracellular ROS plays an important role in the combination treatment-induced p38 MAPK and JNK activations. Pretreatment of NAC completely attenuated the combination treatment-induced p38 MAPK and JNK activations, suggesting that ROS-dependent activations of p38 MAPK and JNK.
Taken together, these results indicate that activation of p38 MAPK is specifically required for translocation of Bax to the mitochondria, and both JNK and p38 MAPK are involved in phosphorylation of $\mathrm{Bcl}-2$ in response to combination treatment with $\gamma$-radiation and $\mathrm{As}_{2} \mathrm{O}_{3}$, and that ROS is a critical regulator of p38 MAPK and JNK activations. The molecular mechanism that we elucidated in this study may provide insight into the design of future combination cancer therapies to cells intrinsically less sensitive to radiation treatment.

\section{Acknowledgments}

This research was supported by the program of Basic Atomic Energy Research Institute (BAERI) which is the Nuclear 
R\&D programs grant from the Ministry of Science and Technology of Korea.

\section{References}

1. Antman KH: Introduction: the history of arsenic trioxide in cancer therapy. Oncologist 6: 1-2, 2001.

2. Soignet SL: Clinical experience of arsenic trioxide in relapsed acute promyelocytic leukemia. Oncologist 6: 11-16, 2001.

3. Shen Y, Shen ZX, Yan H, et al: Studies on the clinical efficacy and pharmacokinetics of low-dose arsenic trioxide in the treatment of relapsed acute promyelocytic leukemia: a comparison with conventional dosage. Leukemia 15: 735-741, 2001.

4. Uslu R, Sanli UA, Sezgin C, Karabulut B, Terzioglu E, Omay SB and Goker E: Arsenic trioxide-mediated cytotoxicity and apoptosis in prostate and ovarian carcinoma cell lines. Clin Cancer Res 6: 4957-4964, 2000

5. Shen ZY, Shen J, Cai W, Hong $\mathrm{C}$ and Zheng MH: The alteration of mitochondria is an early event of arsenic trioxide induced apoptosis in esophageal carcinoma cells. Int J Mol Med 5: $155-158,2000$.

6. Maeda H, Hori S, Nishitoh H, Ichijo H, Ogawa O, Kakehi Y and Kakizuka A: Tumor growth inhibition by arsenic trioxide $\left(\mathrm{As}_{2} \mathrm{O}_{3}\right)$ in the orthotopic metastasis model of androgen-independent prostate cancer. Cancer Res 61: 5432-5440, 2001.

7. Kang YH, Yi MJ, Kim MJ, et al: Caspase-independent cell death by arsenic trioxide in human cervical cells: reactive oxygen species-mediated poly(ADP-ribose) polymerase-1 activation signals apoptosis-inducing factor release from mitochondria. Cancer Res 64: 8960-8967, 2004.

8. Chun YJ, Park IC, Park MT, et al: Enhancement of radiation response in human cervical cancer cells in vitro and in vivo by arsenic trioxide $\left(\mathrm{As}_{2} \mathrm{O}_{3}\right)$. FEBS Lett 519: 195-200, 2002.

9. Antonsson B and Martinou JC: The Bcl-2 protein family. Exp Cell Res 256: 50-57, 2000.

10. Guo B, Godzik A and Reed JC: Bcl-G, a novel pro-apoptotic member of the Bcl-2 family. J Biol Chem 276: 2780-2785, 2001.

11. Ke N, Godzik A and Reed JC: Bcl-B, a novel Bcl-2 family member that differentially binds and regulates Bax and Bak. J Biol Chem 276: 12481-12484, 2001.

12. Oda E, Ohki R, Murasawa H, et al: Noxa, a BH3-only member of the Bcl-2 family and candidate mediator of p53-induced apoptosis. Science 288: 1053-1058, 2000.

13. Hengartner MO: The biochemistry of apoptosis. Nature 407: 770-776, 2000.

14. Green D and Reed JC: Mitochondria and apoptosis. Science 281: 1309-1312, 1998.

15. Blagosklonny MV, Giannakakou VP, El-Deiry WS, Kingstor DG, Neckers L and Fojo T: Raf-1/bcl-2 phosphorylation: a step from microtubule damage to cell death. Cancer Res 57: 130-135, 1997.

16. Srivastava RK, Srivastava AR, Korsmeyer SJ, Nessterova M, Cho-Chung YS and Longo DL: Involvement of microtubules in the regulation of $\mathrm{Bcl} 2$ phosphorylation and apoptosis through cyclic AMP-dependent protein kinase. Mol Cell Biol 18: 3509-3517, 1998.

17. Blagosklonny MV, Schulte T, Nguyen P, Trepel J and Neckers LM: Taxol-induced apoptosis and phosphorylation of $\mathrm{Bcl}-2$ protein involves c-Raf- 1 and represents a novel c-Raf- 1 signal transduction pathway. Cancer Res 56: 1851-1854, 1996.
18. Lee LF, Li G, Templeton DJ and Ting JP: Paclitaxel (Taxol)induced gene expression and cell death are both mediated by the activation of c-Jun NH2-terminal kinase (JNK/SAPK). J Biol Chem 273: 28253-28260, 1998.

19. Ruvolo PP, Deng X, Carr BK and May WS: A functional role for mitochondrial protein kinase Calpha in $\mathrm{Bcl} 2$ phosphorylation and suppression of apoptosis. J Biol Chem 273: 25436-25442, 1998.

20. Haldar S, Jena $\mathrm{N}$ and Croce CM: Inactivation of Bcl-2 by phosphorylation. Proc Natl Acad Sci USA 92: 4507-4511, 1995.

21. Murphy KM, Streips UN and Lock RB: Bax membrane insertion during Fas(CD95)-induced apoptosis precedes cytochrome $\mathrm{c}$ release and is inhibited by Bcl-2. Oncogene 18: 5991-5999, 1999.

22. Desagher S, Osen-Sand A, Nichols A, et al: Bid-induced conformational change of Bax is responsible for mitochondrial cytochrome c release during apoptosis. J Cell Biol 144: 891-901, 1999.

23. Zha J, Weiler S, Oh KJ, Wei MC and Korsmeyer SJ: Posttranslational N-myristoylation of BID as a molecular switch for targeting mitochondria and apoptosis. Science 290: 1761-1765, 2000.

24. Wang X: The expanding role of mitochondria in apoptosis. Genes Dev 15: 2922-2933, 2001.

25. Yin XM, Wang K, Gross A, et al: Bid-deficient mice are resistant to Fas-induced hepatocellular apoptosis. Nature 400: 886-891, 1999.

26. Kyriakis JM and Avruch J: Mammalian mitogen-activated protein kinase signal transduction pathways activated by stress and inflammation. Physiol Rev 81: 807-869, 2001.

27. Tibbles LA and Woodgett JR: The stress-activated protein kinase pathways. Mol Life Sci 55: 1230-1254, 1999.

28. Zhang H, Zhang H, Lin Y, Li J, Pober JS and Min W: RIP1mediated AIP1 phosphorylation at a 14-3-3-binding site is critical for tumor necrosis factor-induced ASK1-JNK/p38 activation. $\mathbf{J}$ Biol Chem 282: 14788-14796, 2007.

29. Ouwens DM, Gomes de Mesquita DS, Dekker J and Maassen JA: Hyperosmotic stress activates the insulin receptor in $\mathrm{CHO}$ cells. Biochim Biophys Acta 1540: 97-106, 2001.

30. Blagosklonny MV: Unwinding the loop of Bcl-2 phosphorylation. Leukemia 15: 869-874, 2001.

31. Srivastava RK, Mi Q, Hardwick JM and Longo DL: Deletion of the loop region of Bcl-2 completely blocks paclitaxel-induced apoptosis. Proc Natl Acad Sci USA 96: 3775-3780, 1999.

32. Matsuzawa A and Ichijo H: Stress-responsive protein kinases in redox-regulated apoptosis signaling. Antioxid Redox Signal 7: 472-481, 2005

33. Gong Y, Sohn H, Xue L, Firestone GL and Bjeldanes LF: 3,3'Diindolylmethane is a novel mitochondrial $\mathrm{H}(+)$-ATP synthase inhibitor that can induce p21(Cip1/Waf1) expression by induction of oxidative stress in human breast cancer cells. Cancer Res 66: 4880-4887, 2006.

34. Wilhelm D, Bender K, Knebel A and Angel P: The level of intracellular glutathione is a key regulator for the induction of stress-activated signal transduction pathways including Jun $\mathrm{N}$-terminal protein kinases and p38 kinase by alkylating agents. Mol Cell Biol 8: 4792-4800, 1997.

35. Probin V, Wang Y and Zhou D: Busulfan-induced senescence is dependent on ROS production upstream of the MAPK pathway. Free Radic Biol Med 42: 1858-1865, 2007. 